\title{
La participación ciudadana. Algunos apuntes a partir del Barómetro Social de España
}

\author{
Public participation in Spain. \\ Some notes based on the Social Barometer of Spain \\ Carlos Pereda \\ Walter ACTIS \\ Miguel Ángel DE PRADA \\ Colectivo Ioé \\ www.colectivoioe.org
}

Recibido: 16/02/2012

Revisado: 29/02/2012

Aceptado: 23/03/2012

Disponible on line: 03/08/2012

\begin{abstract}
Resumen
En el nivel de los principios proclamados, una de las señas de identidad de las democracias occidentales es la participación de la población en la vida política, económica y cultural. En la práctica, sin embargo, la gestión cotidiana de esas esferas corre a cargo de profesionales de la política, corporaciones transnacionales y oligopolios mediáticos. El presente texto trata de recoger las formas de participación de la ciudadanía en el ámbito de la política en un sentido amplio. Si bien la participación indirecta, a través de procesos electorales, ha sido notable durante las tres últimas décadas, la intervención directa en la esfera pública es muy limitada, salvo para una minoría social más activa o en casos excepcionales de movilización colectiva. Tanto los datos aportados por el Barómetro social de España como los sondeos cuantitativos y cualitativos de opinión pública apuntan a que vivimos en una sociedad tecnocrática o plutocrática, más que democrática. El modelo político establecido en España en las últimas décadas ofrece un marco institucional ambivalente para la participación ciudadana: por un lado, se afirma el derecho a la participación y se establecen algunos cauces concretos que antes no existían; por otro, el énfasis en la delegación (mecanismos de representación) impone unos límites precisos a la participación directa en los asuntos públicos.
\end{abstract}

Palabras clave: participación ciudadana, procesos electorales, movilización colectiva, delegación, participación directa.

\begin{abstract}
At the level of proclaimed principles, one of the hallmarks of Western democracy is public participation in political, economic and cultural life. In practice, however, the daily management of these areas is provided by professional politicians, transnational corporations and media oligopolies. This paper seeks to collect in a broad sense the forms of citizen participation in the field of politics. While indirect participation through the electoral process has been remarkable in the last three decades, direct intervention in the public sphere is very limited, except for a more active social minority or, in exceptional cases, of collective mobilization. Both the data from the Social Barometer of Spain as well as quantitative and qualitative surveys of public opinion suggest that we live more in a technocratic or plutocratic society rather than a democratic one. The political model established in Spain in recent decades provides an ambivalent institutional framework for public participation: on the one hand, it affirms the right of participation and sets out some concrete ways that did not exist previously; on the other, the emphasis on delegation (representation mechanisms) imposes restrictions on direct participation in public affairs.
\end{abstract}

Key words: public participation, electoral process, collective mobilization, delegation, direct participation.

Referencia normalizada: Pereda, C.; Actis, W., y De Prada, M. A. (2012): «La participación ciudadana. Algunos apuntes a partir del Barómetro Social de España». Cuadernos de Trabajo Social, 25(2): 309-319.

Sumario: Introducción. 1. Formas de participación indirecta. 2. Formas de participación social directa. 3. Participación en redes asociativas. 4. Tipología de las asociaciones de ámbito estatal. 5. Tiempo dedicado a la participación social. 6. Escasa confianza en las instituciones políticas. 7. Reflexión final. 8. Referencias bibliográficas. 


\section{Introducción}

La evolución de la participación ciudadana durante las últimas décadas ha tenido lugar en España en el contexto de un importante cambio de régimen, desde el autoritarismo franquista hasta la monarquía parlamentaria. La Constitución de 1978 consagra la igualdad de todos los ciudadanos y su derecho a participar en la organización de la vida social. Esto implica un derecho básico que puede ser garantía frente a la falta de libertades del régimen anterior. Sin embargo, en la práctica, tanto la transición política del franquismo a la democracia como la configuración institucional posterior se llevaron a cabo a través de pactos protagonizados por cúpulas dirigentes de distintas fuerzas sociales, subordinando la importante participación popular que había tenido lugar durante el proceso:

Pactos y acuerdos se ofrecían como resultado de un proceso al que los ciudadanos asistían como meros espectadores (...) Esta sería la explicación de la apatía participativa de una población con la que sólo se ha contado en el momento del voto (Del Águila y Montoro, 1984; Ortí, 1988).

\section{Formas de participación indirecta}

El artículo 23 de la Constitución vigente afirma que: «los ciudadanos tienen derecho a participar en los asuntos públicos, directamente o por medio de representantes»; en consecuencia, se reconocen y regulan los derechos de reunión, asociación, manifestación y huelga, así como las consultas a través de referéndum y las iniciativas legislativas populares. Se establecen, además, mecanismos para elegir a los representantes públicos en la Administración local, autonómica, estatal y europea. La participación se manifiesta también en el ejercicio activo de la libre expresión y del debate público y en el grado de confianza o reconocimiento de las instituciones políticas.

Bastantes de estos asuntos se recogen en el Barómetro social de España, en el capítulo sobre Participación ciudadana (Colectivo Ioé, 2008, pp. 311-348), a través de un conjunto de indicadores e índices que se actualizan cada año en el mismo (www.barometrosocial.es). Así, se puede observar que la participación indirecta a través de los procesos electorales ha sido notable. Entre 1977 y 2010, la participación media en las elecciones al Congreso de los Diputados alcanzó el 72 por ciento y en el caso de los Parlamentos autonómicos del 68 por ciento. La participación es sensiblemente menor en las elecciones al Parlamento Europeo, cuya tendencia histórica muestra una curva decreciente, desde un 64 por ciento en 1979 hasta situarse por debajo del 50 por ciento en junio de 2004. En cuanto al mecanismo del referéndum, se ha utilizado sólo cuatro veces desde 1976 y cada vez con menor participación: 78 por ciento el referéndum para la reforma política en 1976; 67 por ciento el referéndum para aprobar la Constitución en 1978; 59 por ciento el referéndum sobre la OTAN en 1986; y 41 por ciento el referéndum para aprobar la Constitución europea en 2005, que finalmente fue retirada por la oposición de Francia y Holanda.

Otra forma establecida de participación es la iniciativa legislativa popular (ILP) que permite introducir una proposición de ley en el Congreso, una vez conseguido un número mínimo de firmas; si bien no se pueden abordar cuestiones referidas a la ley electoral, a las leyes orgánicas, a la hacienda pública o a cuestiones internacionales. La propuesta de iniciativa legislativa popular se tramita en el Congreso, pero no puede ser defendida por la comisión promotora y habitualmente no es aceptada a trámite una vez presentada. Así, cuando se presentó en 1999 la iniciativa legislativa popular por una ley de 35 horas de jornada semanal, con el apoyo de más de 750.000 firmas, el hemiciclo estuvo casi vacío en el momento de explicar la proposición, pero ello no impidió que la mayoría de sus señorías acudiera a votar para no aceptar a trámite la propuesta popular, confirmando de este modo el alejamiento entre las élites políticas (parlamentarias) y la población «activa». Lo mismo ocurrió en 2003 con la iniciativa legislativa popular de estabilidad y seguridad en el empleo, suscrita por 600.000 firmantes.

La ley de Regulación de las Bases del Régimen Local de 1985 reglamenta la participación ciudadana a nivel municipal. Como en el caso de la Constitución, se defiende como principio abstracto la participación directa de los ciudadanos pero, inmediatamente, la propia ley da prioridad al criterio de centralidad en la toma de decisiones - sobre el de participación-y los mecanismos de gestión colectiva de los asuntos públicos quedan excluidos o bien sometidos a unas condiciones que los vuelven prácticamente inviables 
(como la fórmula del referendo local), salvo en el caso de los «consejos» en aquellos pueblos de Castilla donde todavía se conserva esta institución tradicional (que la ley respeta).

\section{Formas de participación social directa}

La participación directa en los asuntos públicos se puede ejercer esporádicamente, por ejemplo acudiendo a una manifestación, o de manera continuada, por ejemplo formando parte de una asociación o militando en un partido político. En ambos casos las formas concretas de participación presentan una gran diversidad y complejidad, lo que explica que la información disponible sobre tales asuntos sea heterogénea y difícil de captar con precisión.

Una encuesta del CIS, aplicada en 2005 y 2009 , permite conocer el grado de participación de la población adulta en diversas formas de intervención esporádica en el campo político (Gráfico 1). Se puede observar que hay una notable continuidad entre los dos años: sólo una parte menor de la ciudadanía, menos de la cuarta parte en el mejor de los casos, había ejercido en el último año alguna de las formas de participación recogidas en el gráfico. No obstante, en torno a la mitad de la población señalaba en ambos sondeos que alguna vez en su vida había participado en acciones de ese tipo, tal como recogemos a continuación:

- Firmar una petición o una protesta: es la acción política más ejercida en los años de aplicación de la encuesta y la que más personas han realizado alguna vez en su vida.

- Boicotear productos por razones políticas, éticas o para favorecer el medio ambiente: dice haberlo realizado en el transcurso del último año en torno al 15 por ciento de la población.

- Acudir a una manifestación: la tasa de participación en manifestaciones varía muchos de unos años a otros según diversas encuestas del CIS, oscilando entre el 30 por ciento de 1996 (Estudio $\mathrm{n}^{\circ} 2.154$ ) y el 12 por ciento de 2009 (Estudio $n^{\circ}$ 2.798). Al margen del grado de consistencia de estas cifras ${ }^{1}$, la mitad de la

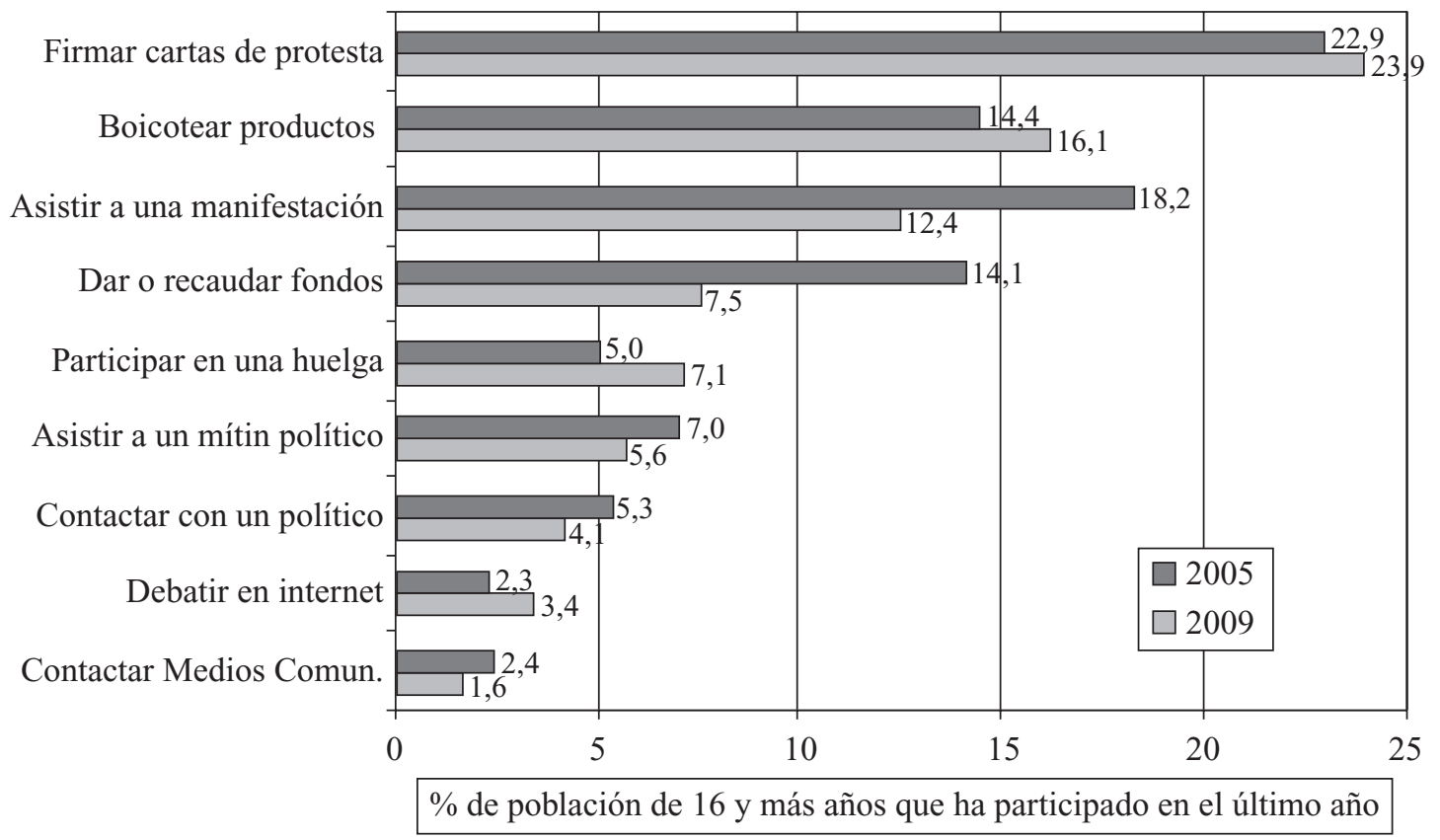

Gráfico 1. Participación directa en diversas formas de intervención social o política.

Fuente: Elaboración propia a partir de las encuestas del CIS nº2.606 (2005, Preg. 19) y nº 2.798 (2009, Preg. 15).

${ }^{1}$ No hemos podido construir una serie con el porcentaje de participación en manifestaciones porque las preguntas de los diversos cuestionarios no son coincidentes. En unos casos se pregunta si se ha manifestado «durante el último año», en otros «en los últimos cinco años»y en otros «alguna vez». 
población española ha participado alguna vez en una manifestación.

- Entregar dinero o recaudar fondos para una actividad social o política: es la actividad concreta que más se ha reducido entre los sondeos de 2005 (14,1 por ciento) y 2009 (7,5 por ciento).

- Participar en una huelga: el 5 por ciento de las personas de 16 y más años afirmaba en 2005 haber participado activamente en una huelga durante el último año mientras que el 7 por ciento lo hizo en 2009. Si tomamos como referencia no el total de los adultos sino sólo a la población activa, estas cifras se elevan al 8 por ciento y 12 por ciento. Podemos comparar estos datos con los de otra encuesta aplicada doce años antes, en 1994, según la cual había participado en una huelga el 37 por ciento de las personas activas. De estas últimas sabemos, además, que el 41 por ciento había acudido «bastantes» $\mathrm{o}$ «muchas veces» a la huelga y que casi la mitad estaba dispuesta a participar «aunque no tuviera el apoyo de los sindicatos» (Encuesta del CIS no 2.088). Es muy probable que la principal barrera para ejercer el derecho de huelga sea precisamente la precariedad laboral: los contratos temporales, la facilidad de despido y el alto desempleo provocan que muchos trabajadores no secunden las huelgas por miedo a represalias.

- Asistir a un mitin político: en 2005 lo hizo un 7 por ciento y en 2009 el 5 por ciento. La asistencia a mítines se incrementa en los años de elecciones (por ejemplo, en 2004 esa proporción se elevó al 12 por ciento).

- Contactar o intentar contactar con un politico para expresarle sus opiniones: lo ha hecho en torno al 5 por ciento de la población adulta. En la Encuesta de 2005 el 46 por ciento de las personas encuestadas afirmaba que nunca recurriría a un político.

- Participar en un foro o grupo de discusión política en Internet: son muy pocos quienes utilizaron esta vía de participación en 2005 y 2009, y con tendencia decreciente, en contra de las previsiones que auguraban una expansión de esta forma de participación en la era digital.

- Contactar o comparecer ante los medios de comunicación para expresar sus opiniones: sólo ha intervenido de este modo el 2 por ciento de la población.

\section{Participación en redes asociativas}

La encuesta antes citada (CIS, 2009) permite conocer el nivel de asociacionismo de la población adulta según diversos tipos de organización. Se distinguen tres situaciones: si pertenecen y participan activamente; si pertenecen pero no participan; y si pertenecieron en el pasado pero no actualmente (Gráfico 2).

La mayoría de la población, entre el 76 por ciento y el 93 por ciento, no participa ni ha participado nunca en los diversos tipos de asociación $\mathrm{y}$, de quienes están adscritos, casi la mitad no participa en ellas de forma activa:

- Sólo dos tipos de agrupación - las deportivas y las culturales o de ocio-superan la barrera del 5 por ciento de la población y en ambos casos los participantes activos son bastantes más que los pasivos.

- La afiliación sindical o empresarial activa es del 3,7 por ciento, casi la mitad de quienes pertenecen pero no participan activamente ( 6 por ciento). La afiliación activa a partidos políticos es del 1,8 por ciento y la pasiva del 1,4 por ciento. Todas estas tasas son muy bajas si tenemos en cuenta que los partidos políticos y los sindicatos y organizaciones empresariales son los principales vehículos de participación directa de la ciudadanía en las esferas política y económica. Dicho de otra manera, ambos indicadores reflejan el establecimiento en España de una democracia de delegación, no de participación.

- El 7 por ciento de la población participa en asociaciones de orientación religiosa, algo más de la mitad de forma activa.

- En proporción parecida (6,8 por ciento) se participa en organizaciones de apoyo social y derechos humanos, algo menos de la mitad de forma activa.

- Casi el 5 por ciento de la población pertenece a corporaciones profesionales y algo menos de la mitad participa activamente.

- Por último, el 2 por ciento de la población forma parte de organizaciones juveniles, de ellos la mitad activamente. Otro 8 por ciento señala haber formado parte de grupos juveniles en el pasado.

\section{Tipología de las asociaciones de ámbito estatal}

Una forma de conocer la frecuencia y características de los diversos tipos de asociación es 


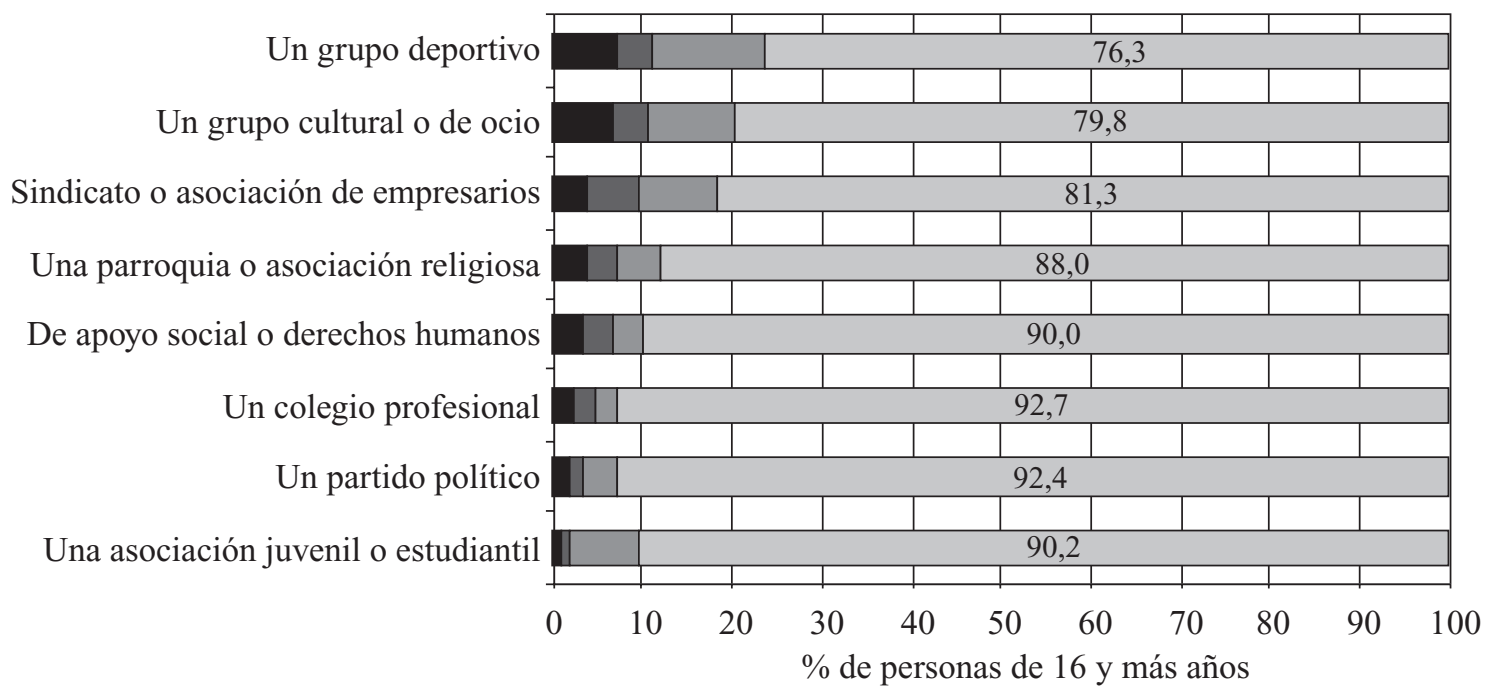

$\begin{array}{ll}\square \text { Pertenece y participa activamente } & \square \text { Pertenece, pero no participa } \\ \square \text { Antes pertenecía, ahora no } & \square \text { Nunca ha pertenecido }\end{array}$

Gráfico 2. Participación en diversas organizaciones (2009).

Fuente: Elaboración propia a partir de la Encuesta del CIS nº 2.798 (2009, Preg. 14).

seguir la evolución de las inscripciones anuales en el Ministerio del Interior, que publica esa información desde hace treinta años. No se inscriben las asociaciones de ámbito autonómico que tienen su propio registro - según el CIRIEC, sumados el ámbito estatal y autonómico, habría en España 151.725 asociaciones inscritas y con alguna actividad en 2008 (Monzón et al., 2010, p. 123) - ni tampoco las sometidas a registros especiales como los partidos políticos, los sindicatos y organizaciones empresariales, o las confesiones religiosas. Se trata de inscripciones o altas que se producen cada año, pero no existe información sobre las bajas que se producen.

El archivo histórico de asociaciones de ámbito estatal recoge 37.000 inscripciones, cuya evolución se plasma en el Gráfico 3. En general se puede observar que las altas se incrementan a lo largo del tiempo, pasando de 6.698 en la década de los años ochenta a 12.247 en la de los noventa y 18.072 en la primera década del siglo XXI. Por tipos de actividad, la clasificación oficial distingue 130 especialidades, que nosotros hemos reducido a 30 , agrupando las que tienen una temática común.

De las actividades asociativas recogidas en el Gráfico 3, sólo 11 han superado las 500 inscripciones en el último quinquenio (2006-2010), destacando las de orientación comercial, las relacionadas con el medio ambiente, las deportivas, las de cooperación al desarrollo y las asistenciales.

El Barómetro social de España recoge en otro indicador la evolución de las asociaciones de ámbito estatal, cuya principal actividad da a entender una orientación cívico-política reivindicativa (Gráfico 4). Las entidades seleccionadas son las de defensa del medio ambiente (ecologistas), derechos humanos, actividades cívico-políticas, de la mujer, movimientos migratorios, cooperación al desarrollo, amnistía y ayuda a penados, y de desarrollo comunitario.

El conjunto de estos tipos de asociación representa una décima parte del total de las inscripciones de ámbito estatal en los últimos treinta años, pero su peso ha experimentado un ritmo creciente al pasar del 11 por ciento en el quinquenio 1996-2000, al 15 por ciento en 2001-2005 y al 20 por ciento entre 2006 y 2010. Las tres modalidades más frecuentes son las de cooperación al desarrollo (31,5 por ciento del total), las de inmigrantes (21,1 por ciento) y las ecologistas (16,5 por ciento). Entre las tres representan más de dos tercios del conjunto de asociaciones «reivindicativas». 


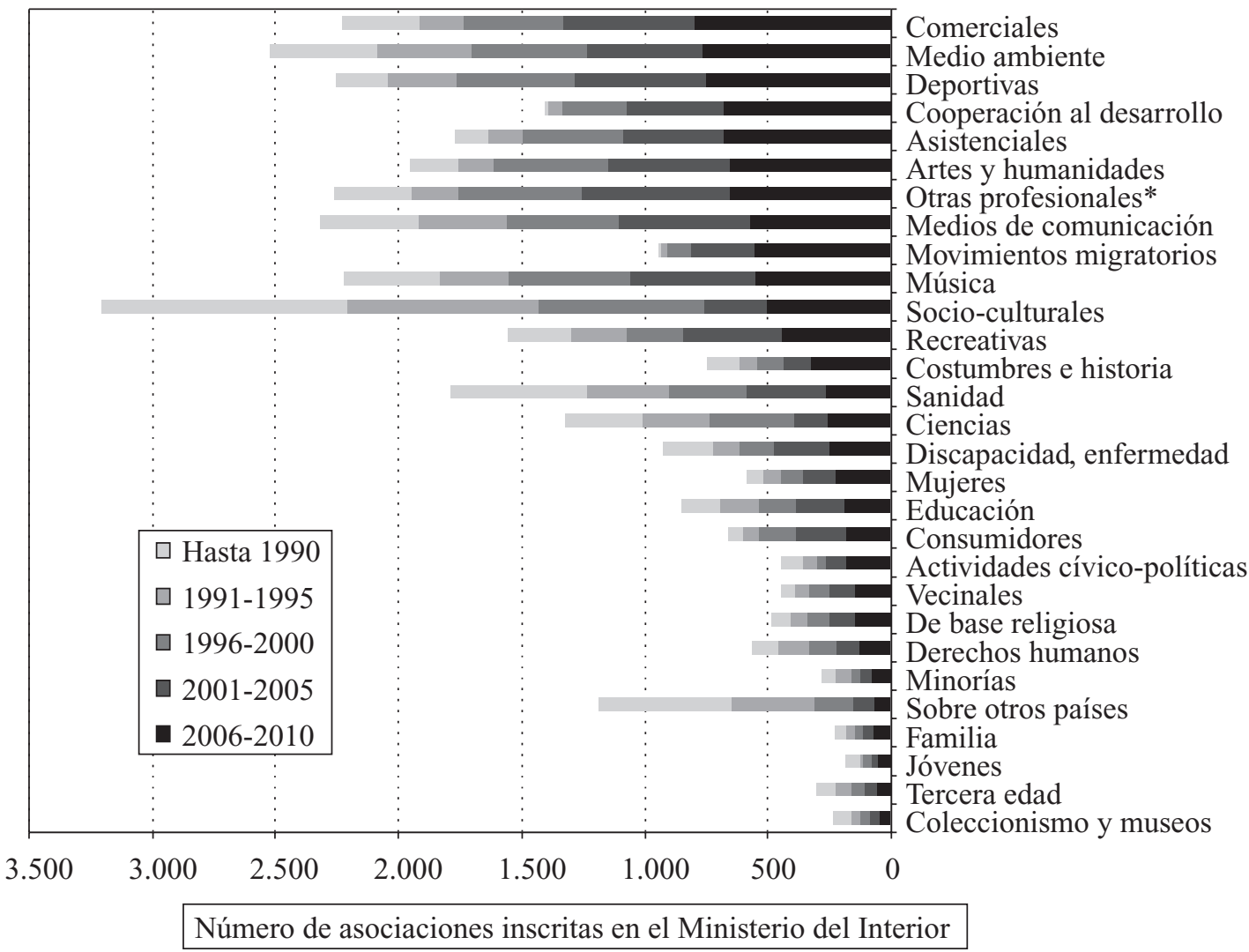

Gráfico 3. Actividades inscritas de ámbito estatal según el tipo de actividad por quinquenios (1980-2010). Fuente: Elaboración del Barómetro Social de España a partir del Anuario Estadístico 2010, del Ministerio del Interior, en www.mir.es

* Las asociaciones profesionales de Sanidad, Educación, Arte y Literatura y Medios de comunicación se recogen en los respectivos apartados.

5. Tiempo dedicado a la participación social La última Encuesta de Empleo del Tiempo, aplicada por el Instituto Nacional de Estadística en 2009-2010, permite saber cuántas personas emplean una parte de su tiempo en actividades de participación social, precisando el tiempo que le dedican (Encuesta estatal, con una muestra de 19.295 personas de 10 y más años, que se aplica en cuatro oleadas para recoger las variaciones a lo largo de un año). Dentro del capítulo «trabajo voluntario y reuniones» aparecen cuatro actividades diferenciadas: trabajo voluntario al servicio de una organización, asistencia a reuniones, ayuda informal a otros hogares y prácticas religiosas. Las dos primeras son representativas de participación ciudadana en el sentido preciso del presente artículo.

Si se suma el tiempo promedio dedicado a las actividades de participación asociativa (trabajo voluntario al servicio de una organización y asistencia a reuniones y actividades de organizaciones sociales), se obtiene una media de 9 minutos a la semana por persona de 10 y más años, una cantidad de tiempo muy inferior a la dedicada al trabajo remunerado y doméstico, así como al tiempo dedicado a ver televisión, usar el ordenador o acudir a prácticas religiosas (Gráfico 5). En relación a siete años antes, cabe destacar el creciente número de personas que dedican tiempo a actividades relacionadas con la informática fuera del tiempo de trabajo, normalmente el uso del ordenador personal, que ha pasado del 18 al 30 por ciento de la población.

\section{Escasa confianza en las instituciones po- líticas}

Para valorar la actitud de la población ante las instituciones políticas de participación indirecta, hemos escogido dos de las mismas: los par- 


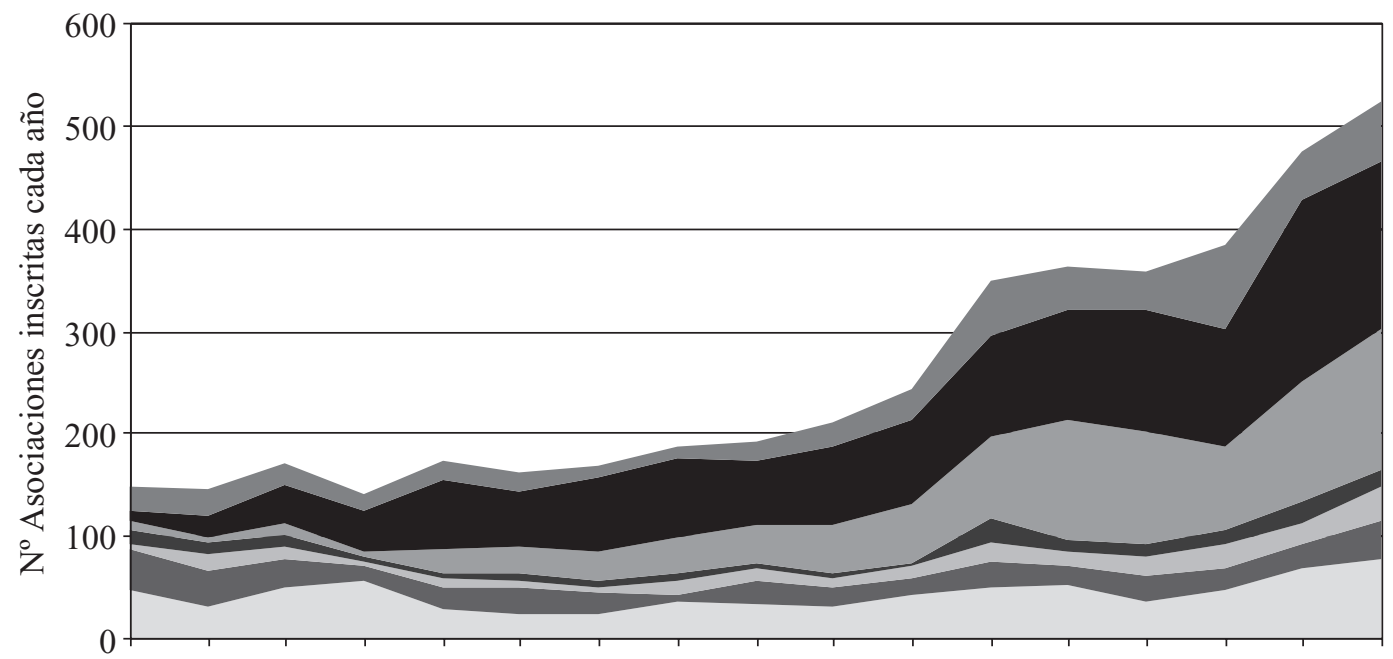

19941995199619971998199920002001200220032004200520062007200820092010

\begin{tabular}{|ll|}
\hline$\square$ Ecologistas & $\square$ Derechos humanos \\
$\square$ Reivindicativas de la mujer & $\square$ Minorías y otros grupos \\
$\square$ Movimientos migratorios & $\square$ Cooperación al desarrollo \\
$\square$ Otras cívico-políticas &
\end{tabular}

Gráfico 4. Inscripción de asociaciones de orientación cívico-política reivindicativa (evolución anual por principales tipos, 1994-2010).

Fuente: Elaboración del Barómetro Social de España a partir del Anuario Estadístico 2010, del Ministerio del Interior, en www.mir.es. Las asociaciones se definen por su principal actividad. Bajo el rubro «otras cívico-políticas» se incluyen «actividades cívico-políticas», de «desarrollo comunitario» y de «amnistía y ayuda a penados».

tidos políticos y el Parlamento. El Gráfico 4 recoge el grado de rechazo que se expresa hacia estas instituciones en el período 1994-2010.

Las mayores críticas se dirigen a los partidos políticos, de los que desconfía en torno a dos tercios de la población (promedio de rechazo del 64 por ciento en los 17 años estudiados); la desconfianza hacia el Parlamento se sitúa en promedio 20 puntos por debajo (media de rechazo del 43,6 por ciento), si bien las oscilaciones son similares en ambos casos. Los picos de descontento coinciden, en parte, con el fin de ciclos políticos que se resuelven con el cambio de mayoría gobernante (1994-95, 2003-04 y 2010-11) y con las etapas de crisis económica (1993-94, en que se llegó a la mayor tasa de paro de la historia de España; minicrisis de 2002 y recesión de 2009):

- El punto de partida (1994) refleja la crispación de la opinión ante ambas instituciones que coincide con la fase final de un desgastado gobierno socialista, acuciado por los escánda- los del GAL y de personajes como Juan Guerra o Luis Roldán, además de la influencia de una fuerte recesión económica que incrementó el paro en más de un millón de personas.

- Con la llegada al poder del Partido Popular en 1996 se inicia un ciclo relativamente largo de estabilización hasta los años 2002-03 en que el descontento vuelve a crecer coincidiendo con la mini-crisis económica de 2002, año en que la sombra del paro volvió a hacerse presente, y con la implicación del gobierno de Aznar en la impopular guerra de Irak, que dio lugar en el mes de febrero de 2003 a algunas de las mayores manifestaciones de protesta de la historia de España.

- En 2004 ambos indicadores evolucionan por primera vez en dirección opuesta: mientras se recupera la confianza en el Parlamento, crece la desconfianza hacia los partidos políticos como efecto de la dura confrontación electoral tras el 11-M en la que los dos partidos mayoritarios se acusaron mutuamente de manipular a la opinión pública. Mejora la situación al ini- 


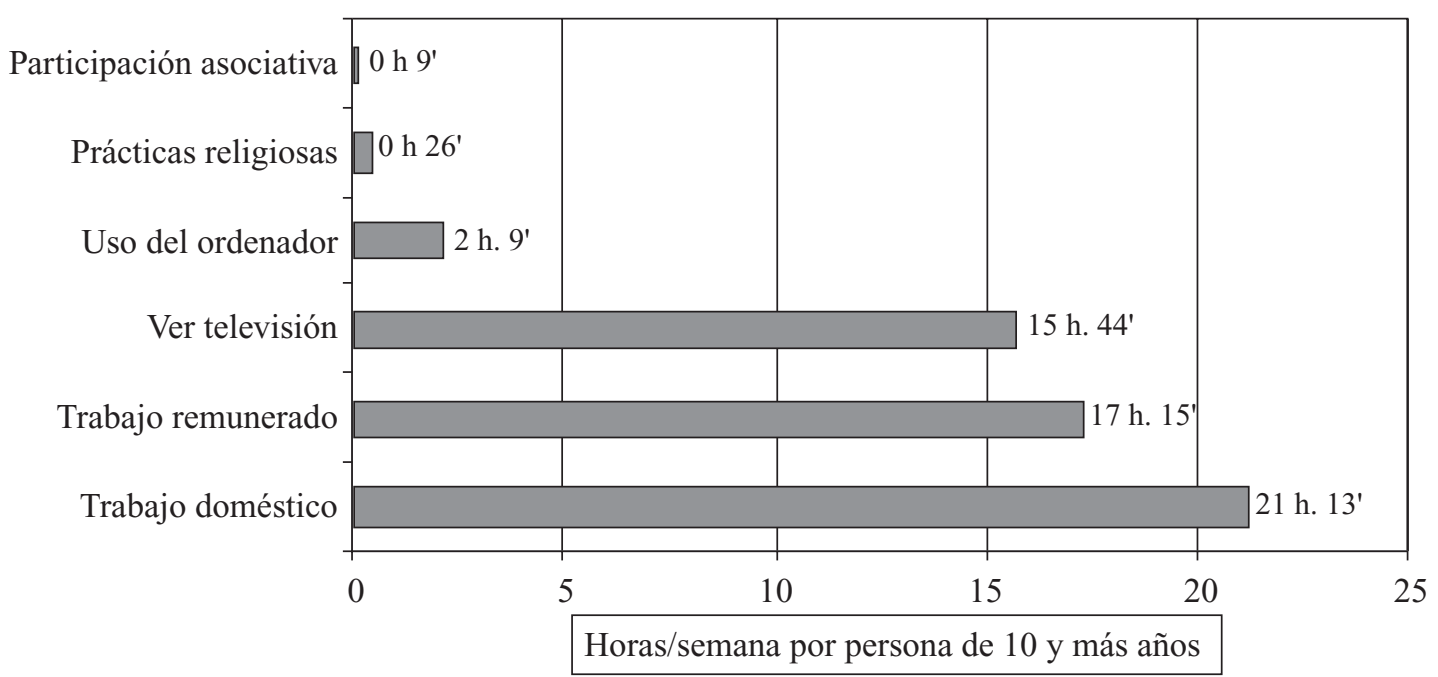

Gráfico 5. Promedio de tiempo semanal* dedicado por la población española a diversas actividades (2010). Fuente: Elaboración propia a partir del INE, Encuesta de empleo de tiempo (2009-2010), en www.ine.es.

* La encuestra del INE proporciona el dato de tiempo dedicado a cada actividad en un día promedio, a partir de las aplicaciones del cuestionario en diversos días de la semana a lo largo del año. Nosotros hemos multiplicado por siete dicho dato para obtener el tiempo promedio semanal.

ciarse la primera legislatura del PSOE en 2005, para evolucionar negativamente desde entonces hasta 2010, sin duda bajo la influencia de la crisis económica de los últimos años.
La crítica a los partidos políticos es una constante en las encuestas realizadas en España en las dos últimas décadas. Habitualmente es la institución social peor valorada y sólo una mi-

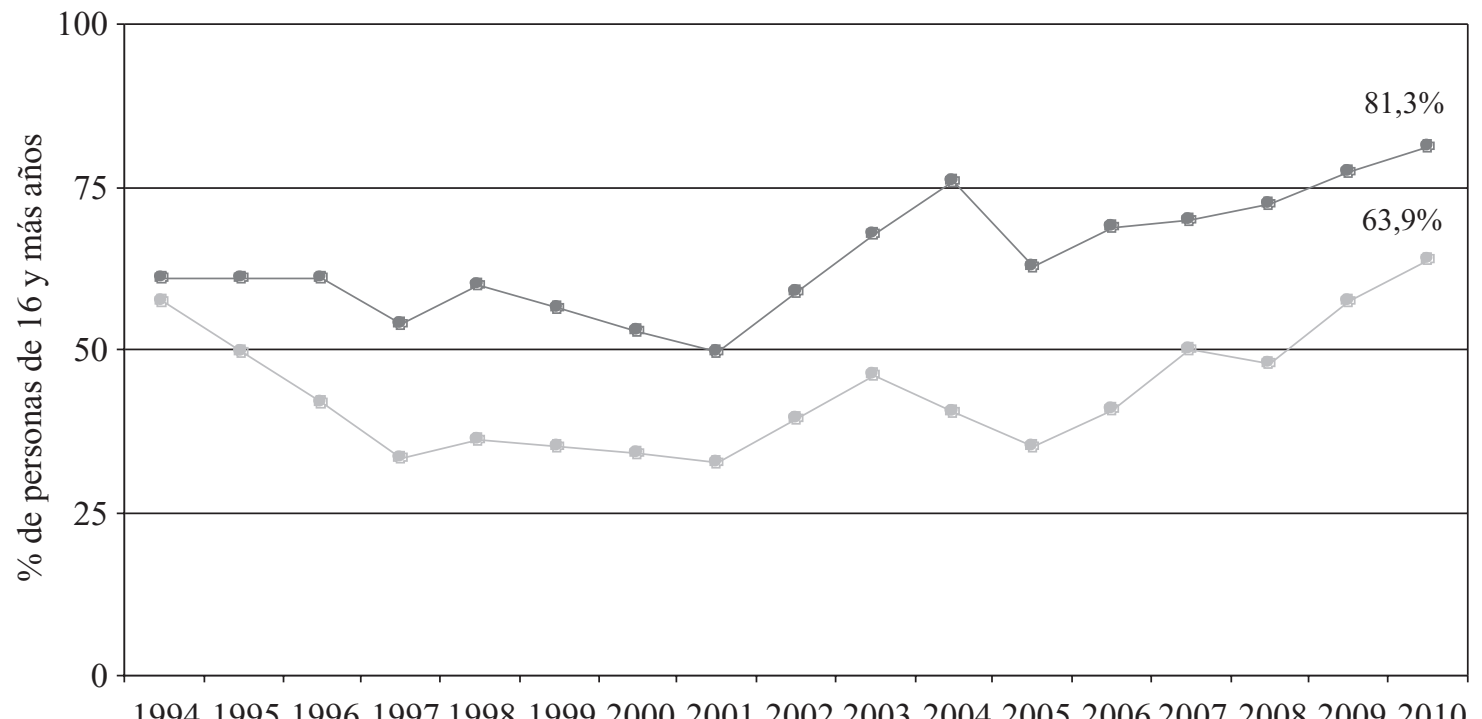

19941995199619971998199920002001200220032004200520062007200820092010

$$
\begin{aligned}
& \text { - Poca o ninguna confianza en el Parlamento } \\
& \text { - Poca o ninguna confianza en los partidos políticos }
\end{aligned}
$$

Gráfico 6. Desconfianza hacia el Parlamento y los partidos políticos (1994-2010).

Fuente: Elaboración del Barómetro Social de España a partir de los Estudios del CIS NN. 2.088, 2.124, $2.218,2.270,2.312,2.417,2.540,2.620,2.663,2.741,2.777,2.823$ у 2.849 . 
noría considera que «los gobernantes actúan de forma adecuada la mayor parte de las veces»; en cambio, la opinión de la mayoría (el 74,2 por ciento en 2009) es que «esté quien esté en el poder, siempre busca sus intereses personales» por encima de los intereses generales (Estudio del CIS, $n^{\circ} 2.790$, pregunta 31 ). La estructura jerárquica de los grandes partidos con opciones de llegar al gobierno, su funcionamiento rígido y su fuerte disciplina, los han convertido en organizaciones que acaparan el poder y la influencia política, frecuentemente en connivencia con los grandes grupos de poder económicos y mediáticos. De este modo, como señala Escudero:

Se ha configurado un modelo de democracia basado en los partidos políticos, a los que constitucionalmente se califica como instrumento fundamental para la participación politica (art. 6), mientras quedan fuera los instrumentos de democracia directa o participativa. En este sentido, difícilmente puede calificarse de modélica una Transición cuyos resultados distan mucho de ser ejemplares en lo que a profundización democrática se refiere (Escudero, 2011, p. 45).

Una encuesta sobre Representación y participación política de 2005 ofrecía una radiografía sobre los partidos políticos y planteaba diversas propuestas para mejorar el funcionamiento de la democracia, entre ellas modificar el sistema electoral mediante listas abiertas, consultar más a la población en cuestiones importantes mediante referendos y crear nuevos mecanismos para que los ciudadanos puedan participar en los procesos de decisión y en el control de la política. Entre las opiniones refrendadas por la mayoría de la población, destaca la falta de democracia interna de los partidos, que funcionaría con una estructura fuertemente piramidal: «en los partidos hay demasiada unanimidad y muy poco debate interno. Los miembros y los cargos de los partidos son demasiado dóciles respecto de sus líderes y carecen de opiniones propias».

Más recientemente, otro estudio sobre $R e$ lación entre economía y política, llevado a cabo mediante metodología cualitativa, detectaba que para la mayoría de la población:
El poder económico ya no está en una capa social o en entidades económicas concretas, sino en la entidad abstracta que forman los Mercados. La correlación de fuerzas entre los poderes económicos y políticos es claramente favorable a los primeros. Hoy el poder último es el poder del dinero (CIS, 2011, pp. 3-4).

En este sentido, el Parlamento y los representantes políticos estarían más pendientes de las exigencias de los mercados (banca, grandes grupos económicos, etc.) que de las demandas y necesidades de la población.

\section{Reflexión final}

El régimen democrático establecido en España en las últimas décadas ofrece un marco institucional ambivalente para la participación ciudadana: por un lado, se afirma el derecho a la participación y se establecen algunos cauces concretos que antes no existían; y por el otro, el énfasis en la delegación (mecanismos de representación) y la presión ejercida por grupos de poder económicos, mediáticos, etc., con frecuencia transnacionales, imponen límites precisos a la participación directa. En un mundo cada vez más interrelacionado, una «clase gerencial transnacional» (Cox, 1993, pp. 172-73) es la encargada de dirigir un colosal proceso de concentración de poder que abarca, no sólo el dominio de los mercados financieros mundiales y el monopolio tecnológico sino también, cada vez más, el acceso a los recursos naturales, el control de los medios de comunicación y el monopolio de las armas de destrucción masiva. En todos estos aspectos se produce un ensamblaje de intereses o complicidad estratégica entre determinados grupos corporativos privados [entre ellos, la Cámara Internacional de Comercio (CIC), el Consejo de Estados Unidos para el Comercio Internacional (USCIB), el Diálogo Transatlántico para los Negocios (TBD), la Mesa Redonda Europea de Industriales (ERT), la Patronal Europea UNICE, etc.) o mixtos (entre ellos, el Foro Económico de Davos (Suiza) y el Club Bilderberg, que reúne todos los años a buena parte de la élite política y económica mundial], los organismos económicos internacionales (Banco Mundial, Fondo Monetario Internacional, Organización Mundial del Comercio, Organización para la Cooperación y el Desarrollo Económico, etc.) y los 
gobiernos de los grandes Estados o bloques políticos como la Unión Europea.

En el contexto anterior, la participación de la ciudadanía en los asuntos públicos, ya se trate de intervenciones puntuales o mediante la cooperación en organizaciones (o si tenemos en cuenta el tiempo dedicado a esas actividades), es mínima, lo que refleja su debilidad como sujetos políticos, capaces de intervenir activamente en los asuntos colectivos que les afectan. El Estado, los partidos y los grupos aludidos de poder han acaparado la gestión de lo político, dando lugar a formas de ciudadanía de baja intensidad, que han provocado el desencanto de gran parte de la población o bien la búsqueda de vías alternativas a los cauces establecidos, vías que amplían su presencia en momentos de recesión económica, cuando las posibilidades de consumo y ocio individualizado se ponen en crisis.

Entre las nuevas vías de participación, los llamados «nuevos movimientos sociales» supusieron hace ya varias décadas la inclusión en el panorama sociopolítico de sujetos con planteamientos alternativos y una nueva forma de hacer política, pero que fueron en parte absorbidos por los discursos y las prácticas del poder (el ejemplo más paradigmático es el Partido Verde alemán, surgido del movimiento ecopacifista, que terminó apoyando las intervenciones de Yugoslavia y Afganistán). A finales de los años noventa surge el movimiento antiglobalización o altermundialista que plantea críticas de fondo al sistema político, económico y cultural dominante, y plantea que «otro mundo es posible», pero sin lograr cambios importantes en la correlación de fuerzas a nivel mundial. Más recientemente, destacan las movilizaciones populares que se iniciaron en el norte de África en los primeros meses de 2011 y se extendieron después por otros países, entre ellos España, a partir de la manifestación del 15 de mayo que ha dado nombre al movimiento $(15 \mathrm{M})$.

El movimiento $15 \mathrm{M}$ fue seguido con interés en sus inicios por más de la mitad de la población española y la mayoría lo valoró positivamente. El Barómetro del CIS de junio de 2011 constató que el 50,2 por ciento de la población española había seguido con mucho o bastante interés «las movilizaciones del llamado movi- miento $15 \mathrm{M}$ o de los llamados indignados que han ocupado distintas plazas de España». A su vez, de quienes habían seguido con interés esas movilizaciones, el 70,3 por ciento las consideraba «positivas» (CIS, 2011). Aunque es pronto para valorar su evolución, apunta a otra forma de entender y hacer la política (Subirats, 2011) que implica una fuerte crítica al modelo de participación existente («no nos representan») y un rechazo frontal al dominio de los poderes económicos sobre la ciudadanía («no somos mercancías en manos de políticos y banqueros»). Para Taibo (2012), el movimiento supone el encuentro de dos almas que se han «vivificado» mutuamente: la de los jóvenes «indignados» procedentes principalmente de clases medias en proceso de desclasamiento a causa de la crisis, que plantean demandas precisas sin cuestionar el orden general del sistema, y la de los movimientos sociales alternativos, que pretenden una contestación general del sistema y se proclaman «orgullosamente anticapitalistas»».

Son frecuentes las referencias al surgimiento de una nueva sensibilidad, que plantea una nueva forma de democracia, tal como recogía Boff a raíz de su participación en el Foro Social Temático de Porto Alegre, en enero de 2012:

$\mathrm{Al}$ escuchar los testimonios vivos de los indignados de España, de Londres, de Egipto y de Estados Unidos, el tema central era «democracia ya». Se reivindica una forma de democracia bien diferente de la que estamos acostumbrados, que es más farsa que realidad. Quieren otra democracia que se construya a partir de la calle, de las plazas, el lugar del poder originario. Una democracia desde abajo, articulada orgánicamente con el pueblo, transparente en sus procedimientos y no corroída nunca más por la corrupción. (...). Es el tiempo nuevo de la subjetividad relacional, la de la emergencia de una conciencia de especie que se descubre dentro de una misma y única Casa Común, que amenaza ruina a causa del excesivo pillaje practicado por nuestro sistema de producción y de consumo (Boff, 2012).

Está por ver si estas movilizaciones son preludio de una nueva democracia o no. El reto está ahí y nos afecta a todas y todos. 


\section{Referencias bibliográficas}

Boff, L. (febrero, 2012). ¿A dónde irán los indignados y los ocupas? Koinonia 475.

CIS (2011). El discurso de los españoles sobre la relación entre economía y política. Nota de investigación sobre estudio cualitativo (Estudio $\mathrm{n}^{\mathrm{0}} 2.865$ ). Madrid: CIS.

CIS. Encuestas No 2.088 (1994), No 2.588 (2002), No 2.606 (2005), No 2.790 (2009), No 2.798 (2009) y No 2.905 (2011). Disponible en www.cis.es.

Colectivo Ioé (2008). Barómetro social de España. Madrid: Traficantes de Sueños.

Cox, R. W. (1993). Fuerzas sociales, estados y órdenes mundiales. En Abelardo Morales (comp.), Poder y orden mundial (pp. 119-196). San José de Costa Rica: FLACSO.

Del Águila R. y Montoro, R. (1984). El discurso politico de la transición española, Madrid: CIS.

Escudero, R. (2011). Democracia, ma non troppo: los mecanismos de participación ciudadana en la Constitución española. Papeles de Relaciones Ecosociales y Cambio Social, 116, 43-53.

INE (2004). Encuesta de empleo del tiempo 2002-2003. Disponible en: www.ine.es.

INE (2011). Encuesta de empleo del tiempo 2009-2010. Disponible en: www.ine.es.

Ministerio del Interior (2011). Anuario Estadístico 2010. Disponible en: www.mir.es.

Monzón, J.L. (dir.) (2010). Las grandes cifras de la economía social en España. Valencia: CIRIEC-España.

Ortí, A. (1988).Transición postfranquista a la monarquía parlamentaria y relaciones de clase: del desencanto programado a la social-tecnocracia transnacional. Política y Sociedad, 2,7-20.

Subirats, J. (2011). Otra sociedad, ¿otra política? Del «no nos representan» a la democracia de lo común. Barcelona: Icaria.

Taibo, C. (febrero, 2012). La deriva del 15M: almas, corrimientos, apoyo mutuo. Madrid15M. 